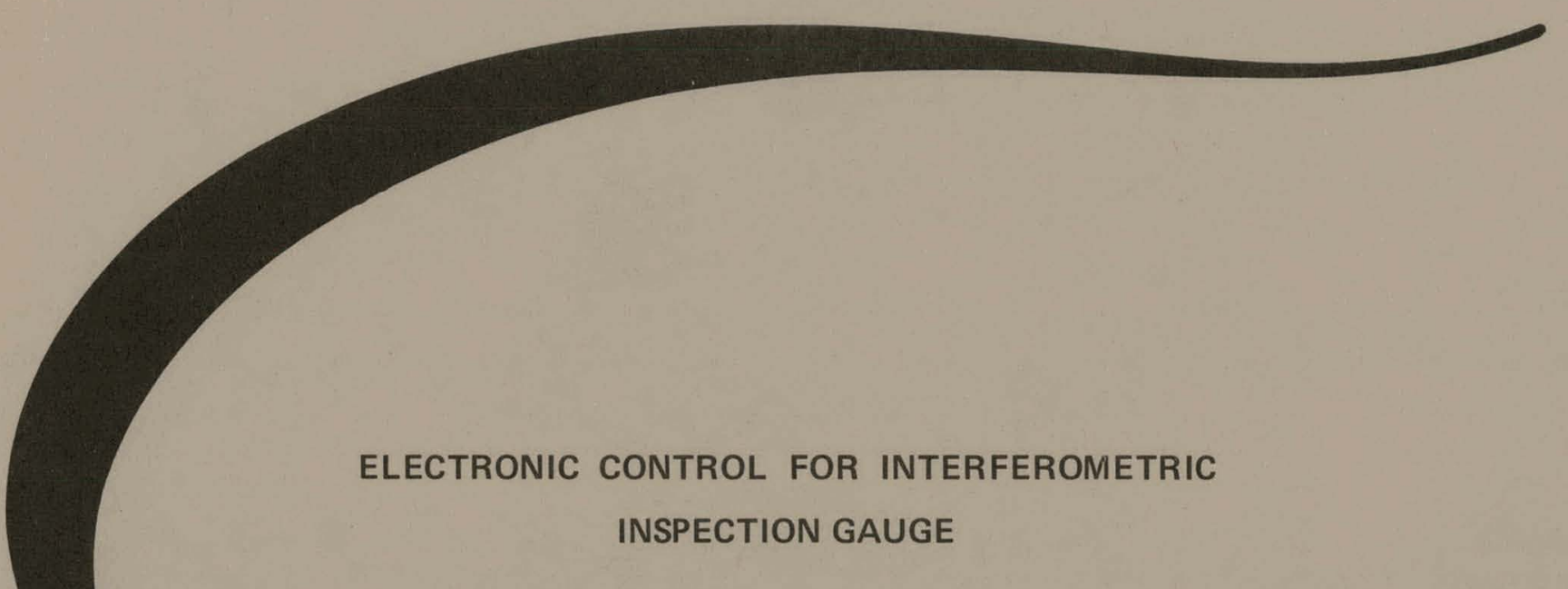

Dennis E. Gunderson

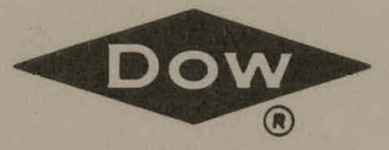

DOW CHEMICAL U.S.A. ROCKY FLATS DIVISION

P. O. BOX 888

GOLDEN, COLORADO 80401

U. S. ATOMIC ENERGY COMMISSION CONTRACT AT(29-1)-1106 


\section{DISCLAIMER}

This report was prepared as an account of work sponsored by an agency of the United States Government. Neither the United States Government nor any agency Thereof, nor any of their employees, makes any warranty, express or implied, or assumes any legal liability or responsibility for the accuracy, completeness, or usefulness of any information, apparatus, product, or process disclosed, or represents that its use would not infringe privately owned rights. Reference herein to any specific commercial product, process, or service by trade name, trademark, manufacturer, or otherwise does not necessarily constitute or imply its endorsement, recommendation, or favoring by the United States Government or any agency thereof. The views and opinions of authors expressed herein do not necessarily state or reflect those of the United States Government or any agency thereof. 


\section{DISCLAIMER}

Portions of this document may be illegible in electronic image products. Images are produced from the best available original document. 


\section{LEGAL NOTICE}

This report was prepared as an account of work sponsorcd by the United States Government. Neither the United States nor the United States Atomic Energy Commission, nor any of their employees, nor any of their contractors, subcontractors, or their employees, makes any warranty, expressed or implied, or assumes any legal liability or responsibility for the accuracy, completeness or usefulness of any information, apparatus, product or process disclosed, or represents that its use would not infringe privately owned rights.

Printed in the United States of America Available from the

National Technical Information Service

U. S. Department of Commerce Springfield, Virginia 22151

Price: Printed Copy $\$ 4.00$ Microfiche $\$ 0.65$ 


\title{
ELECTRONIC CONTROL FOR INTERFEROMETRIC INSPECTION CAUGE
}

\author{
Dennis E. Gunderson
}

Research and Ecology

MECHANICAL GROUP

\begin{abstract}
This itpoit was prepared as un account of wök sponsored by the United States Government. Neither the United States nor the United States Atomic Energy Commission, nor any of their employees, nor any of Commission, nor any of their employees, nor any of their contractors, subcontractors, or their employ makes any wairsinty, express or hipiled, ur assumes any egal liability or responsibility for the accuracy, completeness or usefulness of any information, apparatus, product or process disclosed, or represents that its use would not infringe privately owned rights.
\end{abstract}

DOW CHEMICAL U.S.A. MOCICY FLATS DIVISION

P. O. BOX 888

GOLDEN, COLORADO 80401

Prepared under Contract AT(29-1)-1106

for the

Albuquerque Operations Office

U. S. Atomic Energy Commission
Instrumentation and Cuntrols Inspection

Measurement 
RFP-2014 


\section{CONTENTS}

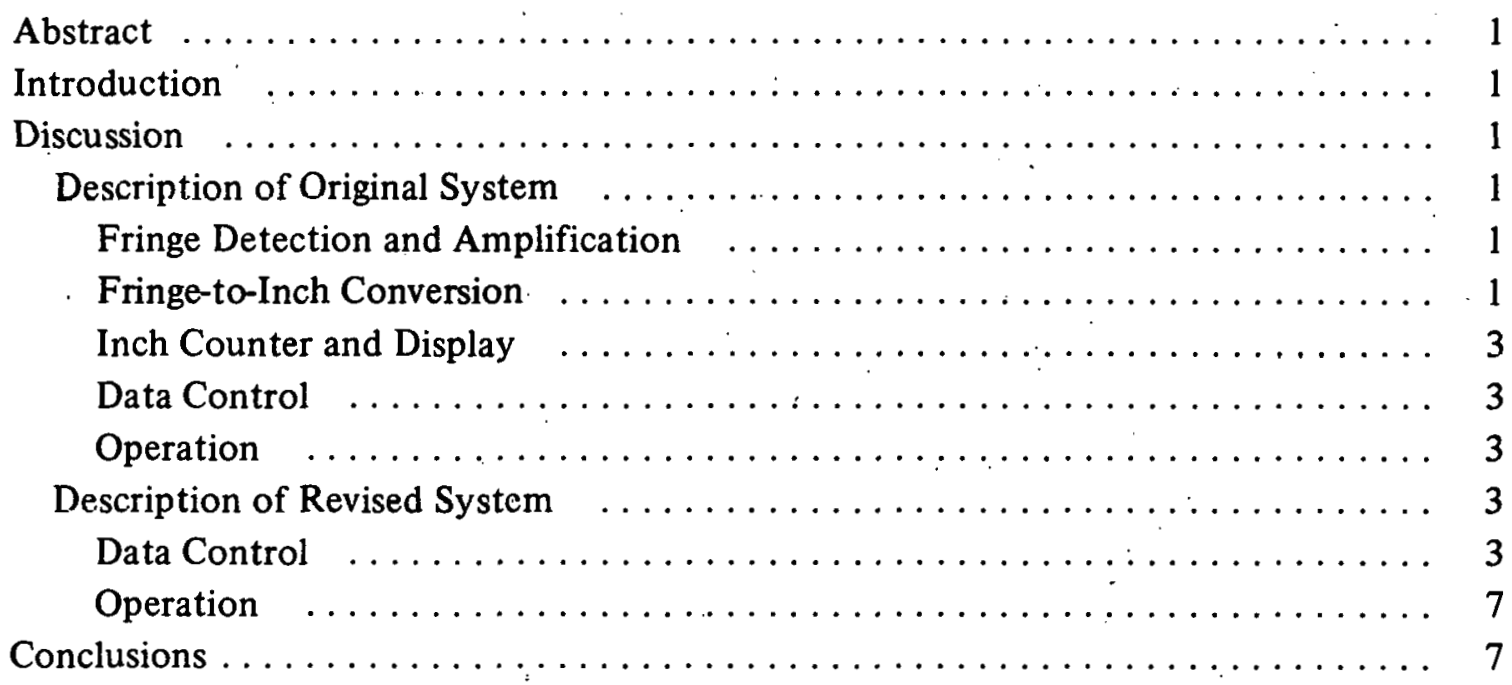


RFP-2014 


\section{ELECTRONIC CONTROL FOR INTERFEROMETRIC INSPECTION GAUGË}

Dennis E. Gunderson

\begin{abstract}
Two gauging systems were developed for the inspection of machined hemispherical parts. Both systems use the same optical gauging arrangement.
\end{abstract}

The data processing and control electronics for the first system required numerous operator manipulations and calculations before and during a part inspection involving lengthy inspection periods.

In the revised electronics package, many manipulations and calculations were eliminated and resulted in manhour savings by shortening and simpliflying part inspections.

\section{INTRODUCTION}

As machining techniques continually improve, parts can be produced with better dimensional accuracy and surface finish. The increased accuracy creates a need for higher resolution inspectiun devices and tèchniques.

To meet the need for more exacting inspection devices, an interferometric dimensional gauging system was developed. The development of the original gauging system led to work on a newly designed system incorporating many improvements.

Both systems employ a modified Michelson interferometer in a gauge-head configuration, which is the fringe source of the optical portion of the system. The gauge head and associated optics have been described in detail in an earlier report. ${ }^{1}$ The current discussion will pertain only to the data processing and control electronics portion of the two different gauging systems.

'G. Wayne Dutton. An Interferometric Displacement Transducer. RFP 1426. Rüuky Flats Division, Dow Chemical Ii.S.A , Golden, Colorado. August 3, 1972.

\section{DISCUSSION}

\section{Description of Original System:}

FRINGE DETECTION AND AMPLIFICATION A block diagram of the original electronics system is shown in Figure 1. Interference fringes produced by the interferometer are sensed by two photodetectors. The photodetectors and optical system are so arranged that the sensed fringe patterns are $90^{\circ}$ out of phase with each other. The quadrature arrangement is necessary for bidirectional fringe counting and permits the detector circuit to achieve a quarter-fringe resolution.

The output of the two photodetectors is fed into two identical preamplifier circuits. The circuits operate in the saturated mode when a bright fringe is incident on the corresponding photodetector and operate in the off mode in the presence of a dark fringe. The circuits also act as a buffer, or driver for the corresponding photodeterstor. Since this gauging system was designed to yield both inner and outer radial information on hemispherical parts, two gauge heads and hence two such detector circuits, each employing two photodetectors and two preamplifiers, were required as noted in Figure 1.

FRINGE-TO-INCH CONVERSION - In order for the fringe information to be meaningful, it must be converted to dimensional data. Therefore, taking the wavelength of the laser, used in the interferometer as:

$$
\text { (lambda) } \lambda=0.63285292 \text { micrometers }
$$

Then the fringe spacing can be determined as ( 0.0254 micrometers $=1$ microinch $)$ :

$$
\frac{\lambda}{2}-12.45773 \text { microinches }
$$


LIGHT FRINGES

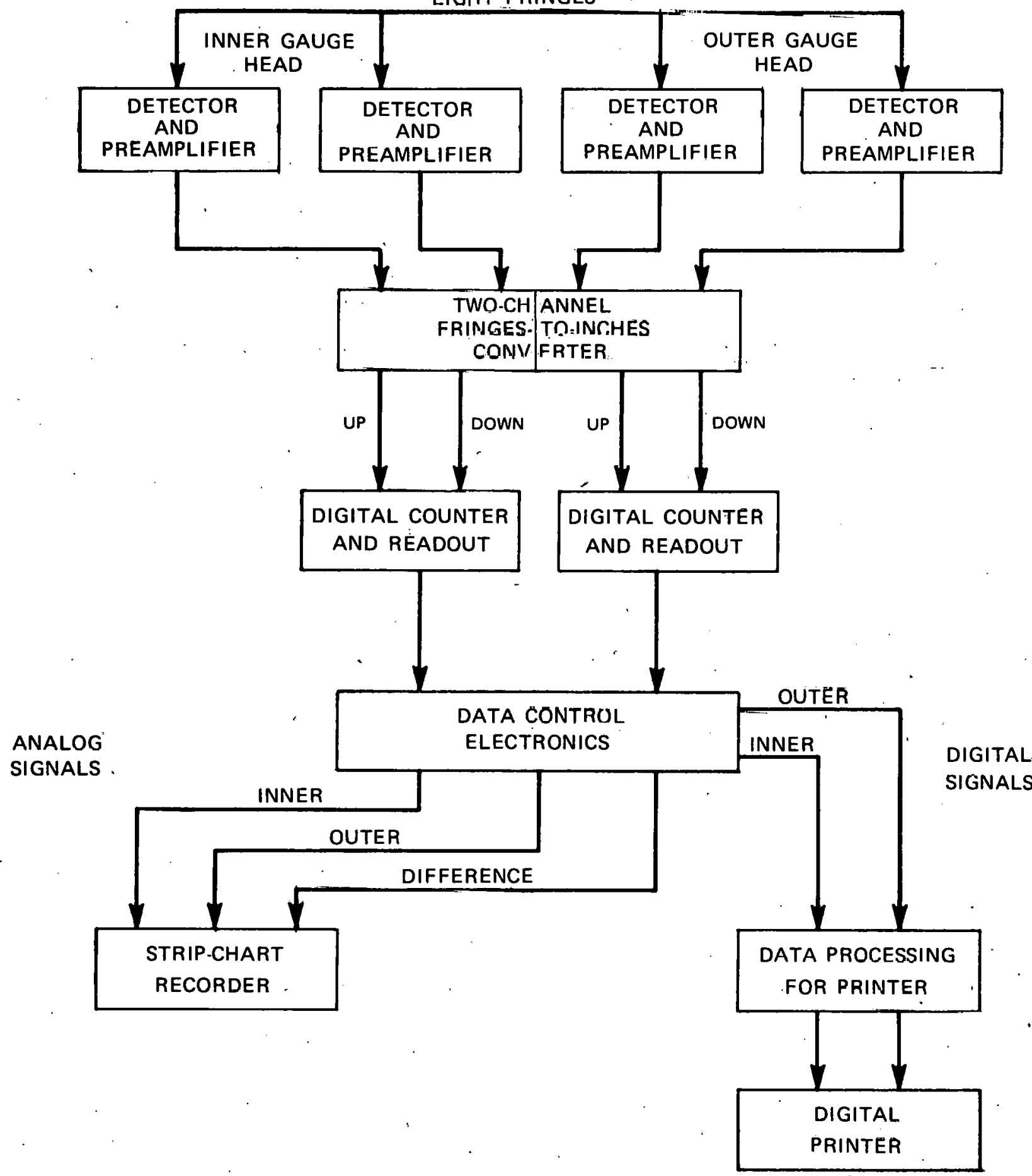

FIGURE 1. Block Diagram of Original Electronic Design for Interferometric Gauging System. 
The conversion from fringes to inches is accomplished y a circuit developed and built at the Y-12 Plant at Oak Ridge, Tennessee. ${ }^{2}$ Instead of converting at the exact rate of 12.45773 microinches per fringe, which would involve considerable electronics, a rounded value of 12.5 microinches per fringe is used. The error accumulating as a result of this approximation can be corrected by periodically dropping one fringe count. The fringe count is dropped at a rate such that the accumulated error never exceeds one fringe $(0.0254$ micrometers $=1$ microinch $)$.

INCH COUNTER AND DISPLAY - The inch information from the fringe-to-inch converter is fed into a purchased bidirectional counter with a nixie-tube display. The counter acts as a visual display as well as an information-storage device.

DATA CONTROL - Dimensional data stored in the counter and displayed on the counter readout are next gated into a digital-to-analog converter. The converter, as its name implies, transforms the digital data displayed on the counter into an analog signal suitable for driving the strip-chart recorder. The analog signals from the digital-to-analog converter, derived from the inner and outer gauge heads, are applied also to a differential amplifier to obtain the wall-thickness data. These three signals are then applied and displayed on three separate channels in the strip-chart recorder.

Simultaneously, the data displayed on the counter can be processed and printed out on a digital printer for a permanent record. The data may be printed out whenever desired by use of a pushbutton control on the operator's control console. The complete operational system is shown in Figure 2.

OPERATION - To inspect an actual hemispherical part, 45 radial sweeps were made around the part in two-degree increments of latitude from the equator to the pole. Figure 3 depicts the inspection procedure for a hemispherical part. For adequate resolution on the strip-chart recorder of

\footnotetext{
${ }^{2}$ C. M. Lay, Fringes-to-Inches Converter for Interferometric. Measurc and Control. Y-DA-2256. Nuclear Division, Y-12 Plant, Union Carbide Corporation, Oak Ridge, Tennessee. April 15, 1968.
}

0.0002 inches per division, observations were not made of the actual part dimensions, but of the difference between the actual and nominal dimensions as the part was being inspected. To better interpret the strip-chart recording, having the zero deviation point occur at the center of the strip chart gave better results. Therefore, at the beginning of each inspection band, the nominal inner and outer radial dimensions had to be manually subtracted from the corresponding actual inner and outer radial dimensions, as indicated by the gauging system, to yield the starting inner and outer radial deviations. An offset constant was then added to these deviations to place zero deviation at the center of the chart. These final two numbers were then pre-set into their respective counters with thumb-wheel switches to establish the proper initial conditions. At this point, the part was rotated and measured to yield inner and outer radial deviation, as well as wall-thickness deviation along this particular band. The procedure was then repeated for the remaining 44 bands.

\section{Description of Revised System:}

After usage of the first prototype gauging system, the gauge functioned as a slow measuring tool when used for production rather than for research and development tasks. The manipulations and calculations made at each two-degree inspection band were both time-consuming and a possible source of human error.

As a result, a new gauge-control console has been designed and built eliminating many of the operator manipulations and calculations.

A flow diagram of the new electronic system is shown in Figure 4. The detection system, fringeto-inch conversion, and digital readout portions of the system remain essentially unchanged.

DATA CONTROL - In the new system (Figure 4), the nominal inner and outer radial dimensions for each two-degree inspection bands are stored on punched paper tape. As needed, the nominal values for a particular inspection band are placed 
RFP-2014



$13823-2$

FIGURE 2. Complete Original System Installed on Inspection Gauge. 


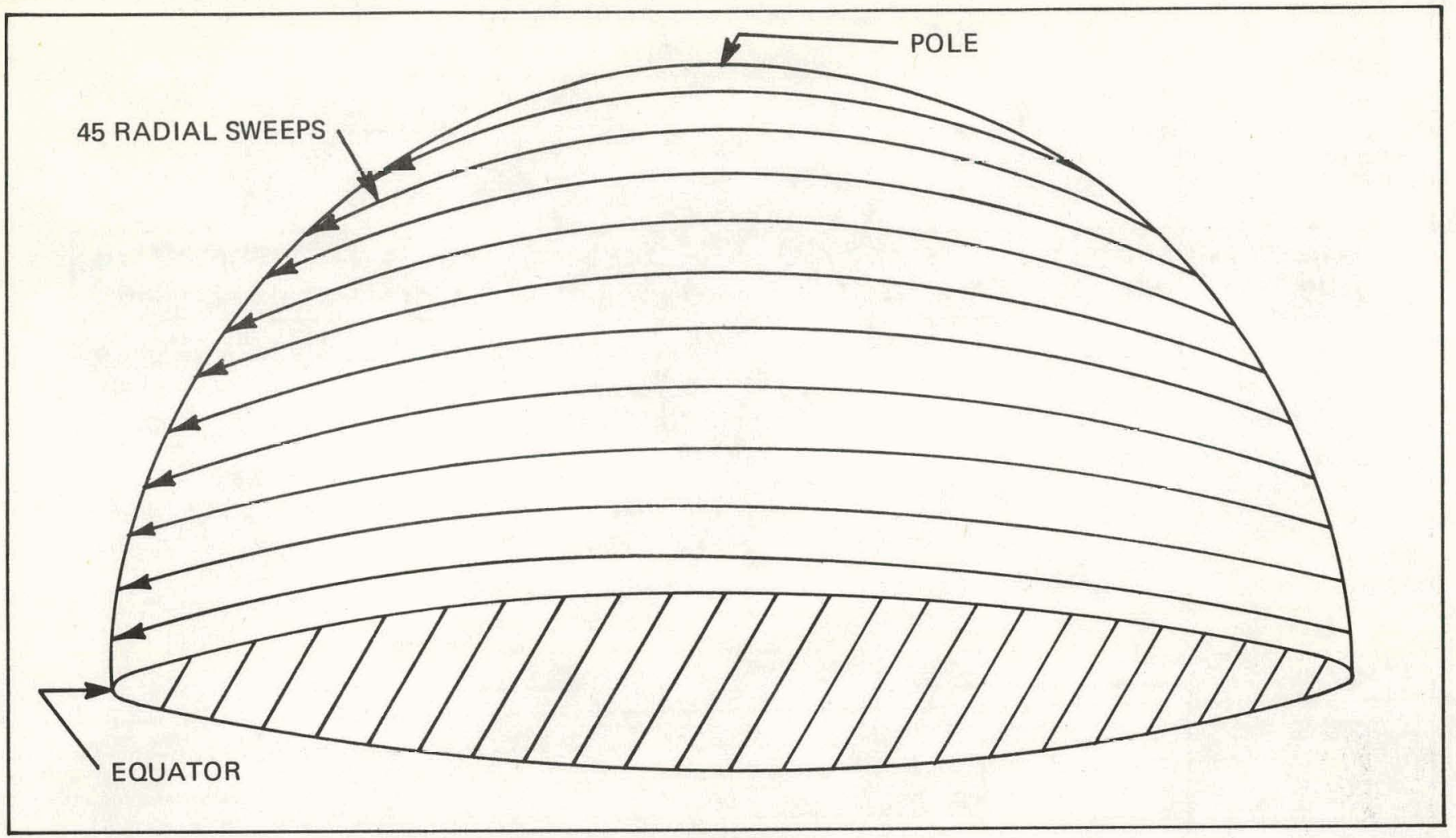

FIGURE 3. Inspection Procedure for a Hemispherical Part.

in temporary data storage with a push-button operation. The actual inner and outer radial information are also placed in temporary data storage and continuously updated. The updating and all remaining digital operations performed on the nominal and actual radial data fall under the timing and control of a master clock.

The dimensional data are all in binary coded decimal (BCD) furm. The nominal and actual data are gated serially, one decade at a time, in to the reversible full subtractor. The reversible full subtractor continuously computes the difference between actual and nominal radial values. The subtraction continues for all six decades of BCD data with only the three least significant decades of difference information being placed in an additional temporary storage register. The subtraction for all six decades must be done to determine if the difference is positive or negative, while only the three least significant decades are needed to determine if the part is within tolerance. If the difference between a particular actual and nominal dimension is negative, the resulting binary difference gives an incorrect value as the logic has not been designed to deal directly with negative differences, and the differences are not transferred to the temporary data storage register. Instead, the reversible full subtractor reverses the two numbers and subtracts nominal from actual. This difference is then transferred to the temporary data storage register along with a digital bit indicating that the difference is negative.

Atter all six decades have been subtracted and the sign determined, the three least significant decades stored in the temporary data storage register are simultaneously transferred to an active storage register whose output drives a three-decade BCD digital-to-analog converter. The output of the digital-to-analog converters, along with their algebraic difference (wall-thickness deviation), is then coupled to the strip-chart recorder for permanent record. Since this particular storage capability is no longer useful with the new design, the digital printer and associated electronics have been eliminated from the system.

The complete gauge console is shown in Figure 5. The heart of the new system is the logic-control 




FIGURE 4. Flow Diagram of Current Electronics System. 
chassis noted in Figure 6 and shown schematically in Figure 7. An enlarged, clearly readable Drawing No. RFP-2014-1 (ozalid copy, 42 by 33 inches) of Figure 7 can be obtained by writing directly to the author.

OPERATION - In actual operation, after positioning the part, the operator pushes a button to clear and preset the initial conditions in the electronics. The operator pushes another button which causes the paper tape reader to read the nominal information for one inspection band and stores this information in a temporary storage register. Then the operator switches the master clock on and rotates the part with all other operations being automatic. At the end of the sweep, the operator increments the part two degrees, pushes the button to obtain new nominal data from the paper tape reader, and

FIGURE 5. Complete Revised Inspection Gauge Console. 15721-3

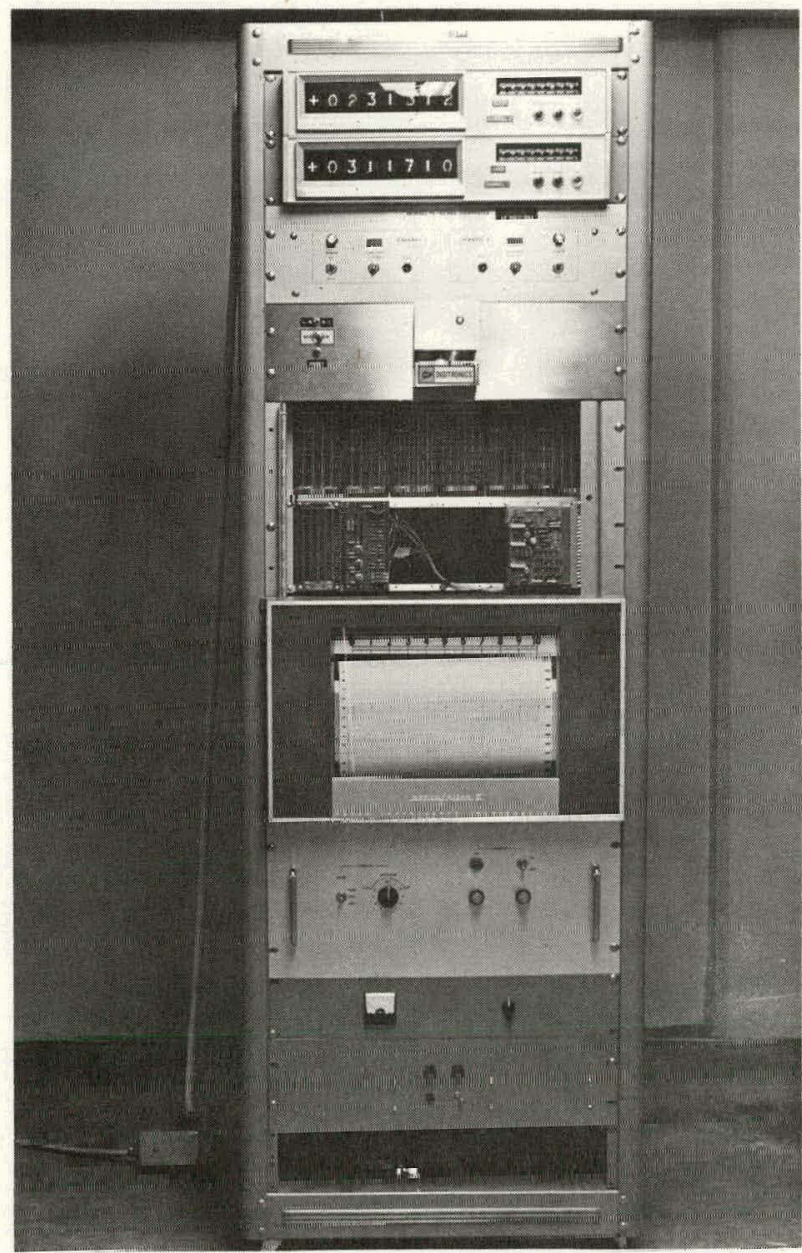

rotates the part. The procedure can be repeated for the remaining inspection bands.

\section{CONCLUSIONS}

As described, the new system eliminates all of the manual operations and calculations previously performed by the operator and replaces them with a few push-button operations. This results in a total part inspection time of approximately 40 minutes as opposed to 2 hours with the original design. Thus, inspection time is greatly reduced and human errors are minimized.

The new gauge console provides improved performance and can be adapted to either commercial or current gauging systems employing a digital readout of the dimensional information.

FIGURE 6. System Logic and Control Chassis.

$16496-4$

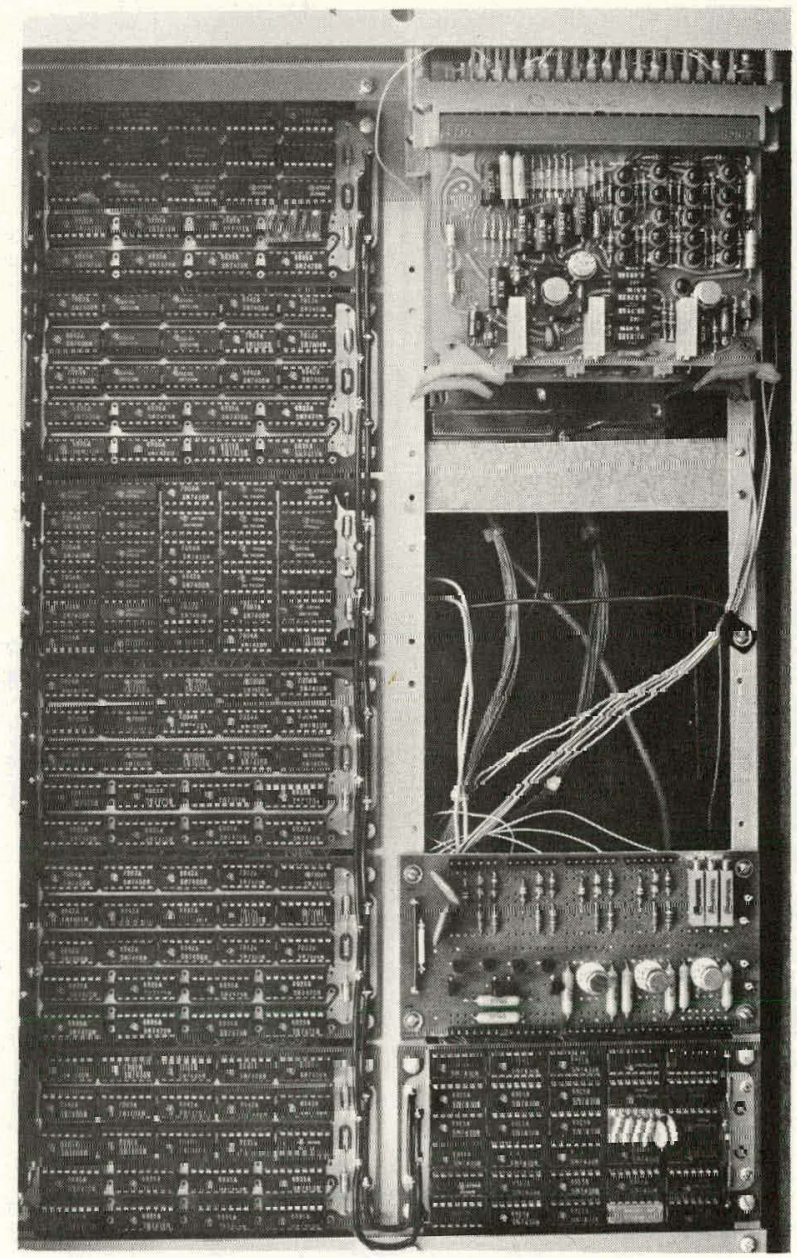


RFP-2014

FIGURE 7. See insert, Drawing No. RFP-2014-1. 


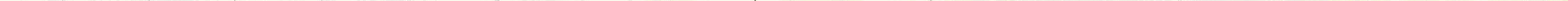

